\title{
A INICIAÇÃO CIENTÍFICA NO BRASIL E SUA PROPAGAÇÃO NO ENSINO MÉDIO
}

\author{
SCIENTIFIC RESEARCH INITIATION IN BRAZIL AND ITS PROPAGATION IN HIGH \\ SCHOOL
}

\author{
Washington Luiz da Costa \\ Universidade Norte do Paraná. washington.costa@ifpr.edu.br \\ Andreia de Freitas Zompero \\ Universidade Norte do Paraná. andzomp@yahoo.com.br
}

\begin{abstract}
Resumo
As instituições escolares são locais privilegiados para que o ensino e a aprendizagem aconteçam. O Ensino Médio, etapa final da Educação Básica, representa o período ideal para a produção científica se solidificar. O presente artigo tem como objetivo apresentar e discutir a literatura relativa à estruturação da Iniciação Científica no ambiente escolar. Para isso, avançamos no universo da Iniciação Científica abordando o seu início de maneira institucionalizada no Brasil por meio da criação do CNPq (Conselho Nacional de Desenvolvimento Científico e Tecnológico) na década de 1950, quando se deu o início ao incentivo financeiro para a pesquisa científica no nosso país, até a escola atualmente. Percorremos também os Documentos Oficiais de Ensino do Brasil que sugerem e citam em seus escritos a propagação da pesquisa e da Iniciação Científica nas escolas. Para finalizar, elencamos alguns programas governamentais que estimulam 0 trabalho científico na escola, oferecendo bolsas financeiras ofertadas aos alunos do Ensino Médio inseridos em programas de pesquisa. As discussões aqui apresentadas poderão promover a compreensão da comunidade acadêmica em relação ao fomento da Iniciação Científica no Ensino Médio nas escolas do Brasil.
\end{abstract}

Palavras-Chave: Iniciação Científica. Ensino Médio. Documentos de ensino. CNPq.

\begin{abstract}
Schools are privileged spaces for teaching and learning take place. High school, final stage of the basic education, represents the ideal moment for solidification of scientific production. This work has had the objective to present and discuss the organization about the Scientific Research Initiation literature at school environment. To achieve this, we advanced into the Scientific Research Initiation universe, covering the beginning of its institutional use in Brazil through the creation of CNPq (Scientific and Technological Development National Council) in the 1950s, when started the financial incentives for scientific research in our country, until the school currently. We also studied the Official Teaching Documents of Brazil that suggest and mention the dissemination of research and Scientific Research Initiation in schools. Finalizing, we list some governmental programs that encourage the scientific work in schools, offering scholarships to High School students
\end{abstract}


enrolled in research programs. The presented discussion can promote the academic community's comprehension of the development of the Scientific Research Initiation in High School in Brazil

Keywords: Scientific initiation. High school. Teaching documents. CNPq.

\section{Introdução}

Em um mundo globalizado repleto de conexões e troca de informações instantâneas, o aluno do século XXI da Geração $Z^{1}$ está envolvido diretamente com várias ferramentas tecnológicas que facilitam o seu dia a dia.

Considerando esse contexto, é possível perceber que os conhecimentos científicos são cada vez mais numerosos. É possível notarmos uma evolução significativa em várias áreas, como médica (radiologia, novos remédios, exames), na tecnológica (internet), no vestuário (novas fibras sintéticas para tecidos, cortes a laser das peças de roupa), na comunicação (fibra ótica), na construção civil (novos materiais, ferramentas e equipamentos) e na educacional, principalmente com relação às ferramentas de ensino que surgiram para auxiliar o dia a dia do professor (quadro interativo, projetores de alta definição, tablets, entre outros).

No momento histórico em que estamos inseridos, é primordial a Iniciação Científica disseminar-se na Educação Básica², atingindo diretamente esse sujeito nativo digital, possibilitando-Ihe utilizar-se de recentes descobertas durante o processo científico, que possam ser aproveitadas em benefício da sociedade, com soluções de qualidade aplicáveis ao contexto social. Assim, o aluno engajado no processo de Iniciação Científica torna-se protagonista no processo de formação.

Para despertar o interesse do aluno da Geração $Z$ pelo ambiente escolar, é fundamental a perspicácia e a persuasão do professor frente a qualquer tema de estudo sugerido. Cabe ao educador mediar e mostrar o caminho a ser percorrido pelo aluno, ajudando-o a transpor barreiras que a própria situação de novas descobertas pode proporcionar, visando sempre à qualidade da formação educacional e pedagógica nesse ambiente tão rico, que é o espaço escolar.

Assim, entende-se que os alunos durante o período de escolarização precisam ter oportunidade de contatos com a pesquisa de maneira sistematizada, apropriando-se cada vez mais da linguagem científica. Sabe-se que esse contato é estreitado somente no Ensino Superior, pois "[...] não há ensino sem pesquisa e pesquisa sem ensino" (FREIRE, 1996, p. 29). Diante de tal reflexão, corroboramos com o autor e refletimos sobre a urgência da importância do fomento à Iniciação Científica (IC) na Educação Básica do Brasil.

Compreender o mérito da Ciência e da Tecnologia (C\&T) para o avanço no desenvolvimento social e econômico de um país é de fundamental importância, mas para

\footnotetext{
${ }^{1}$ A geração Z é formada por indivíduos nascidos a partir de 2001. O "Z" vem de "zapear", "Zap", do inglês, significa "fazer algo muito rapidamente" e também "energia" ou "entusiasmo". Pessoas da Geração Z: [...] "são pessoas dinâmicas e inovadoras, convivem com a tecnologia e a ciência conhecida como nativos da internet, fazem diversas tarefas ao mesmo tempo, são imediatistas, críticos mudam de opinião diversas vezes, preocupados com questões ambientais, serão profissionais mais exigentes, versáteis e flexíveis." (SIQUEIRA, 2012, p. 6).

2 A educação básica é o primeiro nível do ensino escolar no Brasil. Compreende três etapas: a educação infantil, o ensino fundamental e o ensino médio. (BRASIL, 1996).
} 
tal, é necessário que os professores oportunizem aos estudantes o acesso a temas relacionados com questões científicas, socioeconômicas e culturais e a aplicação desses conhecimentos na vida cotidiana; que promovam situações de tomada de decisões em assuntos de interesse público, relacionados com a C \& T. (FOUREZ, 1997)

Nesse sentido, consideramos que os alunos que têm a oportunidade de participar de programas voltados à pesquisa na Educação Básica têm oportunidades de colocar em prática o resultado do trabalho científico e tecnológico deixando de lado a passividade cognitiva. Assim, alfabetizar os cidadãos em ciência e tecnologia é hoje uma necessidade do mundo contemporâneo. (SANTOS; SCHNETZLER, 1997)

Admitimos ser preciso conhecer os caminhos que sugerem a propagação e fomento da Iniciação Científica no Ensino Médio. Assim, neste estudo temos como objetivo apresentar e discutir aspectos da literatura relativa à estruturação da Iniciação Científica no Brasil. Para isso, faremos incursões nos Documentos Oficiais de Ensino do Brasil que oferecem o respaldo para a propagação da pesquisa e Iniciação Científica no âmbito escolar, como a Constituição da República Federativa do Brasil de 1988, a LDB Lei de Diretrizes e Bases n9394/96 e as Diretrizes Curriculares Nacionais Gerais para a Educação Básica de 2013, e por fim, serão apontados alguns programas que promovem o fomento da pesquisa em nosso país como o PBIS - Programa de Bolsas Acadêmicas de Inclusão Social, PIC-OBMEP - Programa de Iniciação Científica da Olimpíada Brasileira de Matemática das Escolas Públicas, PIBIC - Programa Institucional de Bolsas de Iniciação Científica para o Ensino Médio, que é o primeiro programa institucional estruturado para a Iniciação Científica no Brasil, PACE - Programa Complementar de Assistência ao Estudante e o ICJ - Programa de Iniciação Científica Júnior.

\section{A Iniciação Científica: do CNPq à escola}

Um levantamento sobre o início do incentivo à pesquisa no Brasil foi realizado por Massi e Queiroz (2010). De acordo com o estudo, ao se reconhecer a importância estratégica da ciência, observou-se então a necessidade de institucionalizar as ações de incentivo e fomento. Assim, em 1951, foi criado o CNPq - Conselho Nacional de Desenvolvimento Científico e Tecnológico, tendo início o fomento financeiro à pesquisa científica no Brasil.

Este financiamento de Iniciação Científica encontrou respaldo na década de 1960, com a Lei da Reforma Universitária de 1968 (Art. 2ํㅡ, da Lei n. 5.540, de 28/11/1968), que determinou o princípio da "indissociabilidade ensino-pesquisa" como "norma disciplinadora do ensino superior". (MALDONADO apud MASSI; QUEIROZ, 2010)

Mais tarde, essa associação foi incorporada na Constituição de 1988 e, consequentemente, na nova Lei de Diretrizes e Bases da Educação Nacional. (BRASIL, 1996)

A popularização da ciência começou a ser vista como um instrumento para tornar disponíveis às pessoas conhecimentos e tecnologias que ajudem na melhoria da condição de vida e forneçam suporte a desenvolvimentos econômicos e sociais sustentáveis. (BAUMGARTEN apud KERBAUY; ANDRADE; HAYASHI, 2012)

Iniciam-se discussões acerca da Iniciação Científica que, para Simão et al. (1996), foi constituída no interior das universidades brasileiras, onde os alunos eram introduzidos no "universo da pesquisa", sempre sob supervisão de algum professor orientador. 
Segundo Bazin (1983, p. 82), "para criar o Programa de Iniciação Científica, as universidades brasileiras foram buscar inspiração nos países que já tinham uma atividade científica institucionalizada: Estados Unidos e França", ainda nessa linha o autor reitera que, para ele, "a Iniciação Científica pode ser considerada como a etapa seguinte a caminho da independência intelectual". (BAZIN, 1983, p. 83)

Uma definição básica de Iniciação Científica pode ser vista em Houaiss como o "[...] ato de dar ou receber os primeiros elementos de uma prática ou os rudimentos relativos a uma área do saber", (HOUAISS, 2007, p. 1620) sejam eles no ambiente escolar ou profissional que utiliza a Iniciação Científica em suas pesquisas.

Inferindo diretamente sobre o ambiente escolar no Brasil, um dos entraves à propagação da Iniciação Científica é a falta de clareza em relação aos objetivos na formação do aluno ainda no ensino básico, perdendo assim a qualidade na capacitação e na formação do individuo, transformando essa situação, muitas vezes, em evasão escolar.

Na etapa final da escolarização, especificamente no Ensino Médio, Corti (2010, p. 54) ressalta que "o ensino médio se expandiu com base na infraestrutura do ensino fundamental", o país teve nesse período um aumento considerável no número de estudantes no Ensino Médio oriundos das classes populares, porém as escolas não acompanharam esse aumento, o que se tornou um empecilho no fomento da IC nas escolas.

Para Corti (2010, p.54),

[...] essa expansão foi realizada num contexto de baixo investimento público em prédios específicos, sem infraestrutura própria (laboratórios e bibliotecas), material didático e política de valorização aos profissionais de educação, entre outras medidas necessárias. O ensino médio se expandiu com base na infraestrutura do ensino fundamental, e a inclusão de novos públicos acirrou ainda mais um dilema histórico acerca de sua identidade própria e de seus objetivos.

Ferreira et al. (2010, p. 15) alerta ainda para o fato de que, "a escola não prepara adequadamente os jovens para o mundo do trabalho, assim como há pouco estímulo para que sigam carreiras científicas", percebe-se que a instituição escolar está longe de incentivar o jovem a se inserir na Iniciação Científica. Os autores ainda ressaltam que existem "pesquisas no âmbito da juventude e ensino médio que mostram a ausência de políticas públicas voltadas para esse segmento".

Ainda sobre a Iniciação Científica na escola, Bonelli (2010, p. 109-110) sugere que, "um programa de iniciação científica precoce, que se inicia no ensino médio, evidentemente é uma oportunidade para que se enfoquem várias áreas estranguladas no Brasil atual", contribuindo assim para a sustentação desse aluno na escola, diminuindo "a pressão sobre o mercado de trabalho, porque o jovem é mantido por mais tempo na escola, uma escola que talvez esteja mais próxima da preocupação e da necessidade desse jovem".

Assim sendo, a escola tem a missão de oportunizar ações que envolvam a autonomia do aluno em assuntos nos quais a Sociedade está diretamente envolvida, principalmente aqueles que exijam aplicação de conhecimentos científicos na tomada de decisões. (VIEIRA; BAZZO, 2007; SORPRESO, 2008; CUNHA, 2008; CONRADO; ELHANI, 2010) 
Considerando esse aspecto, a escola pode possibilitar aos alunos a inserção na Iniciação Científica, para que o estudante tenha contato diretamente com a maneira como a ciência pode ser produzida e disseminada, descobrindo suas particularidades e seus detalhes intrínsecos.

Admitimos ser de fundamental importância que as práticas de pesquisa na Iniciação Científica estejam presentes durante a Educação Básica e prioritariamente no Ensino Médio, momento que representa a última etapa escolar antes do Ensino Superior.

\section{Documentos oficiais de ensino e a Iniciação Científica}

Nos Documentos de ensino Brasileiros pesquisados, a saber, Constituição da República Federativa do Brasil de 1988, Lei de Diretrizes e Bases de 1996 e Diretrizes Curriculares Nacionais Gerais para a Educação Básica de 2013, encontram-se os respaldos necessários para o fomento da pesquisa e indícios de que a Iniciação Científica deve ser inserida na matriz curricular do Ensino Médio por meio de projetos que ofereçam a possibilidade de participação aos alunos, sejam eles nos contra turnos ou inseridos dentro do planejamento curricular pertinente a disciplina aplicada.

Os Documentos de ensino brasileiros revisados nos remetem às ações que podem ser desenvolvidas em sala de aula, cenário ideal e propício para a busca da excelência científica e a autonomia dos alunos inseridos nas propostas de pesquisa.

Nossa busca na literatura inicia-se com a Constituição da República Federativa do Brasil, documento promulgado pelo Presidente da República, em 05 de Outubro de 1988. Trata-se da sétima versão em vigor no Brasil. A Seção III do Capítulo IV versa sobre o tema da Ciência e Tecnologia. Em seu Art. 218 cita que o Estado promoverá e incentivará o desenvolvimento científico, a pesquisa, a capacitação científica e tecnológica e a inovação, declara que:

$\S 1$ - A pesquisa científica básica receberá tratamento prioritário do Estado, tendo em vista o bem público e o progresso da ciência, tecnologia e inovação.

$\S 2^{\circ}$ - A pesquisa tecnológica voltar-se-á preponderantemente para a solução dos problemas brasileiros e para o desenvolvimento do sistema produtivo nacional e regional.

$\S 3^{\circ}$ - O Estado apoiará a formação de recursos humanos nas áreas de ciência, pesquisa, tecnologia e inovação, inclusive por meio do apoio às atividades de extensão tecnológica, e concederá aos que delas se ocupem meios e condições especiais de trabalho. (BRASIL, 1988)

No seu $\S 3^{\circ}$, lê-se que o Estado "apoiará a formação de recursos humanos nas áreas de ciência, pesquisa, tecnologia e inovação" (BRASIL, 1988, p. 128). Subentendese, pois, que esse apoio poderá e deverá ser fomentado também na escola, que atua diretamente na formação integral do cidadão. 
A Lei de Diretrizes e Bases, sancionada em 20 de Dezembro de 1996, é a terceira em vigor no nosso país, antes desta Lei tivemos a LDB de $1961^{3}$ (BRASIL, 1961) e a de $1971^{4}$ (BRASIL, 1971). Ela estabelece e normatiza as diretrizes e bases da educação nacional. A LDB 9394/96 na seção IV da Educação, no seu Art. 35, item IV, cita que uma das finalidades do Ensino Médio etapa final da Educação Básica, com duração mínima de três anos, é a "compreensão dos fundamentos científico-tecnológicos dos processos produtivos, relacionando a teoria com a prática, no ensino de cada disciplina". (BRASIL, 1996, p. 14)

Já no Art. 36, o currículo do Ensino Médio observará o disposto $§ 1$, item I deste Capítulo, e as seguintes diretrizes:

$\S 1^{\circ}$ Os conteúdos, as metodologias e as formas de avaliação serão organizados de tal forma que ao final do ensino médio o educando demonstre:

I - domínio dos princípios científicos e tecnológicos que presidem a produção moderna. (BRASIL, 1996, p.15)

Salientamos que, nem todos os alunos que fazem o Ensino Médio participam de projetos relacionados à Iniciação Científica, apesar de sugerido nos documentos legais que regem a educação brasileira, tais como a LDB aqui citada, temos alunos que almejam apenas concluir essa etapa do ensino, outros participam de projetos envolvendo outras áreas, tais como, esporte, lazer, cidadania, etc. Portanto nem todos que ingressam no Ensino Médio participam diretamente de projetos científicos na instituição escolar, apesar de corroborarmos com a importância deste tema no Ensino Médio.

As DCNs - Diretrizes Curriculares Nacionais Gerais para a Educação Básica, parecer CNE/CEB №: 7/2010 - são normas obrigatórias (BRASIL, 2010). Esse documento tenta equalizar a aprendizagem, garantindo que os conteúdos básicos sejam ensinados a todos, não deixando de levar em consideração os diversos contextos em que alunos estão inseridos no nosso país.

As Diretrizes orientam as escolas em relação à organização, articulação, desenvolvimento e avaliação de suas propostas pedagógicas e definem uma política de Estado que não depende das gestões de governo.

De acordo com as DCNs (BRASIL, 2013, p. 103-104) a participação da sociedade é necessária. Essa presença se dá por meio do Conselho Nacional dos Secretários Estaduais de Educação (CONSED), da União Nacional dos Dirigentes Municipais de Educação (UNDIME), da Associação Nacional de Pós-Graduação e Pesquisa em Educação (ANPEd), dos docentes, dos dirigentes municipais e estaduais de ensino, dos pesquisadores e dos representantes de escolas privadas.

\footnotetext{
${ }^{3}$ Lei no 4.024, de 20 de Dezembro de 1961, fixava as Diretrizes e Bases da Educação Nacional, é considerada a primeira LDB. http://www2.camara.leg.br/legin/fed/lei/1960-1969/lei-4024-20dezembro-1961-353722-publicacaooriginal-1-pl.html

${ }^{4}$ Lei no 5.692, de 11 de Agosto de 1971, fixava as Diretrizes e Bases para o ensino de $1^{\circ}$ e $2^{\circ}$ graus, e outras providências. http://www2.camara.leg.br/legin/fed/lei/1970-1979/lei-5692-11agosto-1971-357752-publicacaooriginal-1-pl.html
} 
Nas Diretrizes Curriculares Nacionais Gerais para a Educação Básica, o capítulo sobre a etapa final da Educação Básica aponta que, na perspectiva de reduzir a distância entre as atividades escolares e as práticas sociais, o Ensino Médio deve ter uma base unitária sobre a qual podem assentar-se possibilidades diversas:

No trabalho, como preparação geral ou, facultativamente, para profissões técnicas; na ciência e na tecnologia, como iniciação científica e tecnológica; nas artes e na cultura, como ampliação da formação cultural. Assim, o currículo do Ensino Médio deve organizar-se de modo a assegurar a integração entre os seus sujeitos, o trabalho, a ciência, a tecnologia e a cultura. (BRASIL, 2013, p. 40)

A comunidade escolar é importante nesse contexto, pois pode fazer a diferença no processo ensino/aprendizagem, auxiliando e oferecendo subsídios necessários ao crescimento integral do aluno cidadão, tendo o trabalho como princípio educativo e o processo de Iniciação Científica sendo aprimorado durante a escolarização, processualmente conduzido desde a Educação Infantil.

Ainda no mesmo documento no capítulo referente ao Projeto Político e Pedagógico e Regimento Escolar propõe-se que:

[...] a comunidade educacional deve engendrar o entrelaçamento entre trabalho, ciência, tecnologia, cultura e arte por meio de atividades próprias às características da etapa de desenvolvimento humano do escolar a que se destinarem, prevendo: I - as atividades integradoras de iniciação científica e no campo artístico-cultural, desde a Educação Infantil. (BRASIL, 2013, p. 50)

No seu Art. $2^{\circ}$, as Diretrizes Curriculares Nacionais para o Ensino Médio articulamse, com as Diretrizes Curriculares Nacionais Gerais para a:

Educação Básica e reúnem princípios, fundamentos e procedimentos, definidos pelo Conselho Nacional de Educação, para orientar as políticas públicas educacionais da União, dos Estados, do Distrito Federal e dos Municípios na elaboração, planejamento, implementação e avaliação das propostas curriculares das unidades escolares públicas e particulares que oferecem o Ensino Médio. (BRASIL, 2013, p. 194)

De acordo com a citação acima, percebemos que as políticas públicas no Brasil são direcionadas pelo CNE Conselho Nacional de Educação órgão colegiado integrante do MEC (Ministério da Educação e Cultura), que formula e avalia a política nacional da educação, encarrega-se de assegurar a qualidade de ensino e cumprimento da legislação educacional, estabelecendo os rumos da educação em nosso país. Portanto, municípios e estados estão atrelados às diretrizes postuladas e formuladas pelo Conselho e qualquer etapa da Educação Básica está vinculada às políticas públicas atuantes no Brasil.

Nos Documentos de ensino revisados notamos indícios sugerindo a disseminação da Pesquisa, da Ciência e Tecnologia no Ensino Médio. De acordo com a Constituição, a LDB 9394/96 e as Diretrizes Curriculares Nacionais Gerais, verificam-se a presença do incentivo ao fomento da pesquisa na escola, mais precisamente nessa fase de escolaridade. 


\section{O fomento da Iniciação Científica no Ensino Médio}

No fim do século passado, na década de 1990 para Massi e Queiroz (2010, p. 175) foi o "período no qual observamos um crescimento significativo no número de bolsas", é a fase da valorização da Iniciação Científica - IC, definida por Martins e Martins (1999) como o "Período da IC".

Nesta mesma linha de pensamento, Oliveira e Bianchetti (2006, p. 164) afirmam que "uma política de maior investimento no fomento à pesquisa (custeio e capital) pode ser percebida a partir de 1996, embora de forma mais perceptível, de 1999 em diante".

Corti (2010, p. 54) afirma que, "é a partir da década de 1990 que essa expansão ganha contornos de uma real democratização (ou massificação) do ensino".

A busca por uma direção norteadora fez com que essa década fosse marcada por significativas mudanças em relação ao Ensino Médio. Atenta-se para o fato de que somente a partir da LDB 9394/96, o Ensino Médio passou a ser uma etapa do Ensino Básico.

Em 2003 o CNPq criou o programa de Iniciação Científica Júnior que tem o objetivo oportunizar aos alunos da instituição escolar o acesso à pesquisa científica. Segundo Conceição (2012, p.55), o programa tem "um direcionamento para a formação de uma cultura científica, pois os estudantes participarão de atividades de educação científica, ou atividades tecnológicas, sob a orientação de um pesquisador qualificado".

Em relação ao fomento financeiro feito por agências financiadoras de projetos de Iniciação Científica no Brasil no âmbito da Educação Básica, o CNPq, a nível Federal, dividiu-o em duas categorias, as bolsas individuais e as bolsas por cotas.

A nível Estadual, algumas outras agências de fomento, tais como a FAPESP (Fundação de Amparo à Pesquisa do Estado de São Paulo), a FAPERJ (Fundação Carlos Chagas Filho de Amparo à Pesquisa do Estado do Rio de Janeiro) e a FAPEMIG (Fundação de Amparo à Pesquisa do Estado de Minas Gerais), amparam financeiramente os projetos de pesquisa provenientes do Ensino Médio.

Entre as bolsas financeiras mais importantes concedidas pelas agências financiadoras, podemos citar o PBIS - Programa de Bolsas Acadêmicas de Inclusão Social, o PIC-OBMEP - Programa de Iniciação Científica da Olimpíada Brasileira de Matemática das Escolas Pública, o PIBIC - Programa Institucional de Bolsas de Iniciação Científica para o Ensino Médio, o PACE - Programa Complementar de Assistência ao Estudante, além do ICJ - Programa de Iniciação Científica Júnior, que visa ao desenvolvimento de projetos de educação científica com estudantes do Ensino Médio, por meio da concessão de cotas às entidades estaduais parceiras de fomento à pesquisa (Fundações de Amparo à Pesquisa ou Secretarias Estaduais) e outras instituições. Tem por objetivos despertar a vocação científica e incentivar talentos entre estudantes da Rede Pública, possibilitando a participação de alunos do Ensino Médio em atividades de pesquisa científica ou tecnológica, orientada por pesquisador qualificado, em instituições de ensino superior ou institutos/centros de pesquisas.

Conforme afirma Bianchetti et al. (2012) a proposta do CNPq de ampliar a oferta de bolsas de IC para o Ensino Médio e Fundamental pode contribuir para aproximar a graduação e a Educação Básica. Uma das razões apontadas pelos autores é a necessidade do domínio do conhecimento científico e tecnológico e a capacidade de transformá-lo em inovações para a inserção do país e das empresas no mercado globalizado. 
Portanto, consideramos com relação às contribuições pessoais que, a Iniciação Científica no Ensino Médio pode ser "utilizada como ferramenta educacional, e sua contribuição para a construção de um cidadão reflexivo, no exercício da sua autonomia e de seu discernimento crítico diante do contexto político, econômico e social em que está inserido". (COSTA, 2015, p.8)

Se optar pelo Ensino Superior no futuro, os subsídios adquiridos podem the ser útil, estando este aluno engajado em alguma modalidade de pesquisa universitária sistematizada, se não optar pela continuação dos seus estudos, levará os mesmos valores para a sua vida adulta, como profissional e cidadão.

\section{Considerações finais}

Sabe-se que o fator primordial e determinante para uma escola são o ensino e a aprendizagem. Segundo a Constituição da República Federativa do Brasil de 1988, no seu Art. 205, "A educação, é direito de todos e dever do Estado..." (BRASIL, 1988, p. 121). Sendo assim, o estado possui a obrigação de proporcionar e facilitar o acesso à educação em todos os âmbitos sejam eles no Ensino Básico, Ensino Superior ou Ensino Profissionalizante, proporcionando diversas ferramentas e instrumentos que possibilitem a execução desse processo.

A criação do CNPq, na década de 1950, foi um grande ganho para a sistematização da pesquisa em nosso país. O crescimento das descobertas científicas proliferou, algumas com reconhecimento internacional. Portanto, a Iniciação Científica nesse âmbito escolar tem uma grande significância para continuar esta evolução científica.

Todos os documentos revisados em nosso trabalho amparam a disseminação da Iniciação Cientifica e da pesquisa no sistema educacional. O professor pode utilizar-se desse amparo institucional para mediar este contato entre aluno e Iniciação Científica, pois considera-se que "[...] o professor medeia a relação ativa do aluno com a matéria, inclusive com os conteúdos próprios de sua disciplina" (LIBÂNEO, 2009, p. 13). Desse modo, poderá proporcionar inúmeras estratégias que possibilitem o caminhar do processo educativo, problematizando, questionando, dialogando, ouvindo os alunos, ensinando-os a argumentar, aguçando-Ihes a criticidade, contribuindo positivamente na construção da autonomia e abrindo-lhes espaço para expressarem seus pensamentos, sentimentos, desejos, de modo a permitir que tragam para a aula sua realidade vivida.

Percebe-se que muitos dos programas que fomentam e possibilitam aos estudantes desenvolverem pesquisas na escola, podem ser desconhecidos dos professores. A falta de informação nos ambientes escolares é grande, e pode dificultar o processo de Iniciação Científica, pois são os professores que darão início aos projetos de pesquisa, garantindo que os alunos concorram diretamente às bolsas oferecidas pelas agências financiadoras de pesquisa.

A distância diminuiu entre o Ensino Médio e o Ensino Superior após o CNPq iniciar o fomento e a distribuição de bolsas financeiras. Entretanto, ainda existem instituições escolares que permanecem no ostracismo, e essa inércia educacional contribui negativamente para a não propagação da pesquisa e da Iniciação Científica no Ensino Médio.

Por fim, reiteramos, portanto, a importância da Iniciação Científica e a necessidade de que esta seja aprofundada no Ensino Médio, por oportunizar aos alunos conhecer e 
vivenciar processos da ciência, como também contribuir satisfatoriamente para a compreensão e entendimento dos alunos com relação ao dia a dia da Sociedade em que vive.

\section{Agradecimentos}

Agradecemos a Capes pelo auxílio financeiro por meio de bolsas de ensino/pesquisa para realização deste trabalho.

\section{Referências}

BAZIN, M. J. O que é a iniciação científica. Revista de Ensino de Física, São Paulo, v. 5, n. 1, p. 81-88, jun. 1983.

BIANCHETTI, L. et al. A iniciação à pesquisa no Brasil: políticas de formação de jovens pesquisadores. Educação, Santa Maria, v. 37, n. 3, p. 569-584, set./dez. 2012.

BONELLI, M. G. Os desafios que a juventude e o gênero colocam para as profissões e o conhecimento científico. In: FERREIRA, Cristina (Org.). Juventude e iniciação científica: políticas públicas para o ensino médio. Rio de Janeiro: EPSJV, UFRJ, 2010. p. 107-120.

BRASIL. Conselho Nacional de Educação. Parecer CNE/CEB № 7/2010. Diretrizes Curriculares Nacionais Gerais para a Educação Básica. Disponível em: <http://www.nepiec.com.br/lesgislacao/pceb007_10.pdf>. Acesso em: 15 mar. 2017.

BRASIL. Constituição (1988). Constituição da República Federativa do Brasil. Disponível em: <http://www.planalto.gov.br/ccivil_03/constituicao/constituicao.htm>. Acesso em: 15 mar. 2017.

BRASIL. Lei no 4.024, de 20 de dezembro de 1961. Fixa as Diretrizes e Bases da Educação Nacional. Disponível em: <http://www2.camara.leg.br/legin/fed/lei/19601969/lei-4024-20-dezembro-1961-353722-publicacaooriginal-1-pl.html>. Acesso em: 15 mar. 2017.

BRASIL. Lei no 5.692, de 11 de agosto de 1971. Fixa Diretrizes e Bases para o ensino de $1^{\circ}$ e $2^{\circ}$ graus, e dá outras providências. Disponível em: <http://www2.camara.leg.br/legin/fed/lei/1970-1979/lei-5692-11-agosto-1971-357752publicacaooriginal-1-pl.html>. Acesso em: 15 mar. 2017.

BRASIL. Lei no 9.394, de 20 de dezembro de 1996. Estabelece as diretrizes e bases da educação nacional. Disponível em: <http://www.planalto.gov.br/ccivil_03/leis/L9394.htm>. Acesso em: 15 mar. 2017.

BRASIL. Ministério da Educação. Diretrizes curriculares nacionais gerais da educação básica. Brasília: MEC, 2013. Disponível em: <http://portal.mec.gov.br/docman/julho-2013pdf/13677-diretrizes-educacao-basica-2013-pdf/file>. Acesso em: 15 mar. 2017.

CORTI, A. P. O. Que ensino médio queremos? Uma experiência de diálogo com escolas públicas. In: FERREIRA, Cristina Araripe (Org.). Juventude e iniciação científica: políticas públicas para o ensino médio. Rio de Janeiro: EPSJV, UFRJ, 2010. p. 53-80. 
CONCEIÇÃO, A. J. Contribuições do Programa de Iniciação Científica Júnior na Universidade Estadual de Londrina (UEL): a formação de um habitus adequado ao campo científico. Dissertação (Mestrado Profissional em Políticas Públicas) Universidade Estadual de Maringá, Centro de Ciências Humanas, Letras e Artes, Programa de Pós-Graduação em Ciências Sociais, 2012.

CONRADO, D. M.; EL-HANI, C. N. Formação de cidadãos na perspectiva CTS: reflexões para o ensino de ciências. In: SIMPÓSIO NACIONAL DE CIÊNCIA E TECNOLOGIA, 2., 2010, Ponta Grossa. Anais... Ponta Grossa: UTFPR, 2010.

COSTA, W. L. A CTS (Ciência, Tecnologia e Sociedade) na compreensão dos alunos que participam da iniciação científica no Instituto Federal do Paraná. 2015. $114 \mathrm{f}$. Dissertação (Mestrado em Metodologias para o Ensino de Linguagens e suas Tecnologias) - Centro de Pesquisa em Educação e Tecnologia, Universidade Norte do Paraná, Londrina, 2015.

CUNHA, A. M. Ciência, tecnologia, e sociedade na óptica docente: construção e validação de uma escala de atitudes. 2008. Dissertação (Mestrado) - Faculdade de Educação, Universidade Estadual de Campinas, Campinas, 2008.

FERREIRA, C. A. et al. (Org.). Juventude e iniciação científica: políticas públicas para o ensino médio. Rio de Janeiro: EPSJV; UFRJ, 2010. Disponível em: <http://newpsi.bvspsi.org.br/eventos/Juventude-IniciacaoCientifica.pdf>. Acesso em: 18 mar. 2017.

FOUREZ, G. Scientific and technological literacy as a social studies of science. Social Studies of Science, Canada, v. 27, n. 6, p. 903-936, 1997. Disponível em: http://sss.sagepub.com/content/27/6/903.

FREIRE, P. Pedagogia da autonomia: saberes necessários à prática educativa. São Paulo: Paz e Terra, 1996.

HOUAISS, A. Dicionário eletrônico da língua portuguesa. 2007. Disponível em: <http://houaiss.uol.com.br/busca.jhtm>. Acesso em: 19 mar. 2017.

KERBAUY, T. M.; ANDRADE, T. H. N.; HAYASHI, C. R. M. (Org.). Ciência, tecnologia e sociedade no Brasil. Campinas: Alínea, 2012.

LIBÂNEO, J. C. Adeus professor, adeus professora?: novas exigências educacionais e profissão docente. 9. ed. São Paulo: Cortez, 2009.

MALDONADO, L. A. Iniciação científica na graduação em nutrição: autonomia do pensar e do fazer na visão dos pesquisadores/orientadores. Dissertação de Mestrado - Faculdade de Educação, Universidade do Estado do Rio de Janeiro, Rio de Janeiro. 1998.

MARTINS, R. C. R.; MARTINS, C. B. Programas de melhoria e inovação no ensino de graduação. Estudos e Debates: Uma Política de Ensino Superior, Brasília, v. 20, p. 189221, mar. 1999.

MASSI, L.; QUEIROZ, S. L. Estudos sobre iniciação científica no Brasil: uma revisão. Cadernos de Pesquisa, São Paulo, v. 40, n. 139, p. 173-197, 2010.

OLIVEIRA, A.; BIANCHETTI, L. CNPq: política de fomento à pesquisa nos governos Fernando Henrique Cardoso (FHC). Perspectiva, Florianópolis, v. 24, n. 1, p. 161-182, jan./jun. 2006.

SANTOS, W. L. P.; SCHNETZLER, R. P. Educação em química: compromisso com a cidadania. ljuí: UNIJUÍ, 1997. 
SIMÃO, L. M. et al. O papel da iniciação científica para a formação em pesquisa na pós graduação. In: SIMPÓSIO DE PESQUISA E INTERCÂMBIO CIENTÍFICO DA ASSOCIAÇÃO NACIONAL DE PESQUISA E PÓS GRADUAÇÃO EM PSICOLOGIA, 6., 1996. Rio de Janeiro. Anais... Rio de Janeiro: Anppep, 1996. p. 111-113.

SIQUEIRA, R. N. Métodos de ensino adequados para o ensino da geração $Z$, uma visão dos discentes. In: ENANGRAD, 23., 2012, Bento Gonçalves. Anais... Bento Gonçalves, RS, 2012.

SORPRESO, T. P. Organização de episódios de ensino sobre a "questão nuclear" para o ensino médio: foco no imaginário de licenciados. 2008. Dissertação (Mestrado) - Faculdade de Educação, Universidade Estadual de Campinas, Campinas, 2008.

VIEIRA, K. R. C. F.; BAZZO, W. A. Discussões acerca do aquecimento global: uma proposta CTS para abordar esse tema controverso em sala de aula. Ciência \& Ensino, Campinas, v. 1, n. esp. 2007.

Submissão: 28/10/2014

Aceite: $23 / 02 / 2017$ 